\title{
In vitro activity and in vivo efficacy of the saponin diosgenyl 2-amino-2-deoxy- $\beta$-D-glucopyranoside hydrochloride (HSM1) alone and in combination with daptomycin and vancomycin against Gram-positive cocci
}

Oscar Cirioni, ${ }^{1}$ Henryk Myszka, ${ }^{2}$ Malgorzata Dawgul, ${ }^{3}$ Roberto Ghiselli, ${ }^{4}$ Fiorenza Orlando, ${ }^{5}$ Carmela Silvestri, ${ }^{1}$ Lucia Brescini, ${ }^{1}$ Wojciech Kamysz, ${ }^{3}$ Mario Guerrieri ${ }^{4}$ and Andrea Giacometti ${ }^{1}$

Correspondence

Andrea Giacometti

a.giacometti@univpm.it

Received 24 February 2011

Accepted 19 April 2011

\author{
${ }^{1}$ Institute of Infectious Diseases and Public Health, Università Politecnica delle Marche, Ancona, \\ Italy \\ ${ }^{2}$ Faculty of Chemistry, University of Gdansk, Gdansk, Poland \\ ${ }^{3}$ Faculty of Pharmacy, Medical University of Gdansk, Gdansk, Poland \\ ${ }^{4}$ General Surgery and Surgery Methodology Clinic, Università Politecnica delle Marche - Ospedali \\ Riuniti, Ancona, Italy \\ ${ }^{5}$ Experimental Animal Models for Aging Units, Research Department, INRCA IRRCS, Ancona, Italy
}

\section{INTRODUCTION}

Hospital- and community-acquired Gram-positive infections pose a substantial burden in terms of morbidity, mortality and health-care costs (Cormican \& Jones, 1996; Linden, 1998). Surgical site infections are the second most

Abbreviations: ANOVA, analysis of variance; FIC, fractionary inhibitory concentration; HSM1, diosgenyl 2-amino-2-deoxy- $\beta$-D-glucopyranoside hydrochloride; MBC, minimal bactericidal concentration; MRSA, meticillin-resistant Staphylococcus aureus; MSSA, meticillin-susceptible Staphylococcus aureus; VR, vancomycin resistant; VS, vancomycin susceptible. common of these, with the US Centers for Disease Control and Prevention estimating that about 500000 surgical site infections occur annually in the USA (Bratzler et al., 2004; Burke, 2003). Surgical site infections are the biological summation of several factors: the inoculum of bacteria introduced into the wound during the procedure, the unique virulence of contaminants, the microenvironment of each wound and the integrity of the patient's host defence mechanisms (Bratzler et al., 2004; Burke, 2003; Hirsch et al., 2010).

The increasing multidrug resistance of these organisms due to overuse and failure to apply basic infection control 
policies and procedures has created a need for the development of new antimicrobial agents to treat these infections (Bouza, 2009; Bratzler et al., 2004; Burke, 2003; Hirsch et al., 2010; Linden, 1998; Moellering 1998). However, the introduction of new antibiotics to counter these pathogens has frequently been closely followed by the emergence of resistant strains (Cormican \& Jones, 1996; Fisher \& Phillips, 2009; Raad et al., 1998). The use of natural therapeutic products is as ancient as human civilization and, for a long time, minerals, plants and animal products were the main sources of drugs. For this reason, in recent years, there has been growing interest in alternative therapies and in the therapeutic use of natural products (Saleem et al., 2010). The search for alternative therapeutics is growing and, in particular, it is becoming critical to identify effective agents to treat multidrug-resistant Grampositive infections with novel mechanisms of activity. Saponins were originally classified as any of various plant glycosides and marine organisms that form soapy lathers when mixed and agitated with water, and thus have been used routinely as detergents, foaming agents and emulsifiers (Saleem et al., 2010; Yang et al., 2006). These natural surfactants were later found to be mainly glycosides of steroids and triterpenes, which exist widely in terrestrial plants, including many significant foods, forage crops and herbal medicinal plants (Qi et al., 2006; Simons et al., 2006). So far, thousands of homogeneous saponins have been isolated and characterized. One of the most important groups of saponins is the diosgenyl glycosides (Myszka et al., 2003). These compounds show a wide variety of biological functions, which may partially be ascribed to the sapogenin moiety and partially to the carbohydrate residue. They are also good antifungal and antibacterial agents and show antiinflammatory activity (Aremu et al., 2010; Di Liberto et al., 2010; Wallace, 2004). Among these activities, haemolysis is probably the most general one shared by many structurally disparate saponins. It is believed that these saponins can form complexes with sterols of the erythrocyte membrane, thus causing an increase in permeability and the subsequent loss of haemoglobin. However, the detailed mechanism of action of this haemolytic cascade remains unclear (Myszka et al., 2003; Yang et al., 2006). Diosgenyl 2-amino-2-deoxy$\beta$-D-glucopyranoside hydrochloride (HSM1) is an unnatural saponin. Until now, there have been no known steroidal saponins containing amino sugars. Only some triterpenoid saponins have $\mathrm{N}$-acetyl-D-glucosamine in the carbohydrate moiety. Various biological activities have been observed for diosgenyl saponins, including anticancer, antibacterial and antifungal activities (Myszka et al., 2003). We have designed and synthesized this unnatural saponin with a $\beta$-Dglucosamine residue attached to the 3-hydroxyl group of the diosgenyl backbone. The presence of the $-\mathrm{NH}_{2}$ group in the sugar moiety will allow the preparation of several analogues with different constituents at this group in the future.

The aim of the present study was to evaluate the in vitro activity of HSM1 against a large number of Gram-positive cocci, as well as to investigate its in vivo efficacy in an animal model of staphylococcal and enterococcal wound infection.

\section{METHODS}

Organisms. The following quality-control strains were used: meticillin-susceptible Staphylococcus aureus (MSSA) ATCC 29213, meticillin-resistant Staphylococcus aureus (MRSA) ATCC 43300, vancomycin-susceptible (VS) Enterococcus faecalis ATCC 29212, vancomycin-resistant (VR) E. faecalis ATCC 51299, Rhodococcus equi ATCC 6939 and Streptococcus pyogenes ATCC 19615. In addition, 100 nosocomial Gram-positive cocci isolated from patients with wound infections and admitted to the Ospedali Riuniti, Ancona, Italy, were tested.

\begin{abstract}
Antimicrobial agents. HSM1 was synthesized from commercially available D-glucosamine hydrochloride in several steps. The reaction of this sugar with tetrachlorophthaloyl anhydride, acetylation with acetic anhydride in pyridine and bromination of the anomeric centre of D-glucosamine with $\mathrm{TiBr}_{4}$ gave the glycosyl donor 3,4,6-tri - $O$-acetyl-2-deoxy-2-tetrachlorophthalimido- $\alpha, \beta$-D-glucopyranosyl bromide. Glycosylation of diosgenin with this bromide gave a fully protected glycoside: diosgenyl 3,4,6-tri-O-acetyl-2-deoxy-2tetrachlorophthalimido- $\beta$-D-glucopyranoside. This glycoside was deprotected by treatment with hydrazine hydrate in ethanol (Myszka et al., 2003). Finally, for biological research, this glycoside was converted into the hydrochloride (HSM1).
\end{abstract}

Vancomycin, erythromycin and doxycycline (Sigma-Aldrich), imipenem (Merck, Sharp \& Dohme), ciprofloxacin (Bayer), daptomycin (Novartis) and linezolid (Pfizer) were also tested as control agents.

MIC and minimal bactericidal concentration (MBC) determination. Solutions of drugs were freshly prepared on the day of assay or stored at $-80{ }^{\circ} \mathrm{C}$ in the dark for a maximum of 2 weeks. The concentration range assayed was $0.125-64 \mathrm{mg} \mathrm{l}^{-1}$ for HSM1 and $0.25-256 \mathrm{mg} \mathrm{l}^{-1}$ for the other antimicrobial agents.

MICs were assayed at $5 \times 10^{5}$ c.f.u. $\mathrm{ml}^{-1}$ in Mueller-Hinton (MH) broth by a microbroth dilution method according to the procedures outlined by the Clinical and Laboratory Standards Institute (formerly the National Committee for Clinical Laboratory Standards) (NCCLS, 2003). The MIC was taken as the lowest drug concentration at which observable growth was inhibited. The MBC was taken as the lowest concentration of each drug that resulted in a $>99.9 \%$ reduction in the initial inoculum. Experiments were performed in triplicate.

Bacterial killing assay. The ATCC control strains were used to study the in vitro killing effect of HSM1. Aliquots of exponentially growing bacteria were resuspended in fresh $\mathrm{MH}$ broth at $\sim 10^{7}$ cells $\mathrm{ml}^{-1}$ and exposed to HSM1 at $2 \times$ MIC for $0,5,10,15,20,25,30,40$, 50 and $60 \mathrm{~min}$ at $37^{\circ} \mathrm{C}$. After these times, samples were serially diluted in $10 \mathrm{mM}$ HEPES ( $\mathrm{pH}$ 7.2) to minimize the carryover effect and plated onto $\mathrm{MH}$ agar plates to obtain viable colonies.

Synergy studies. In interaction studies, six strains of MSSA, six of VS E. faecalis, six of R. equi and six of S. pyogenes were used to test the antibiotic combinations by a chequerboard titration method using 96-well polypropylene microtitre plates. The ranges of drug dilutions used were $1-64 \mathrm{mg} \mathrm{l}^{-1}$ for HSM1 and $0.25-256 \mathrm{mg}^{-1}$ for the clinically used antibiotics. The fractionary inhibitory concentration (FIC) index for combinations of two antimicrobials was calculated according to the equation FIC index $=\mathrm{FIC}_{A}+\mathrm{FIC}_{B}=A / \mathrm{MIC}_{A}+B /$ $\mathrm{MIC}_{B}$, where $A$ and $B$ were the MICs of drug $A$ and drug $B$ in combination, $\mathrm{MIC}_{A}$ and $\mathrm{MIC}_{B}$ were the MICs of drug $A$ and drug $B$ 
alone, and $\mathrm{FIC}_{A}$ and $\mathrm{FIC}_{B}$ were the FICs of drug $A$ and drug $B$, respectively. The FIC index was interpreted as follows: $<0.5$, synergy; 0.5-4.0, indifferent; $>4.0$, antagonism (Eliopoulos \& Moellering, 1996).

Cytotoxicity assay. For the cytotoxicity assay, A549 cells from a human lung carcinoma (BioWhittaker) were cultured in $25 \mathrm{~cm}^{2}$ tissue culture flasks in Dulbecco's modified Eagle's medium with $10 \%$ fetal calf serum (BioWhittaker). The cytotoxicity of HSM1 at 1$2 \times$ MIC was determined using a CellTiter 96 AQueous cell proliferation assay (Promega).

Animals. Adult male BALB/c mice weighing 35-50 g were used for all experiments ( $n=12$ per group). All animals were housed in individual cages under a constant temperature $\left(22^{\circ} \mathrm{C}\right)$ and humidity with a $12 \mathrm{~h}$ light/dark cycle, and had access to chow and water ad libitum throughout the study. The environment was temperature and humidity controlled, with lights on and off at 06.30 and 18.30. The study was approved by the animal research ethics committee of the INRCA IRRCS, Università Politecnica delle Marche, Ancona, Italy.

Preparation of inocula. The quality-control strains MSSA ATCC 29213 and VS E. faecalis ATCC 29212 were prepared for use in an in vivo setting. Bacteria were grown in brain-heart infusion broth. When the bacteria were in the exponential phase of growth, the suspension was centrifuged at $1000 \mathrm{~g}$ for $15 \mathrm{~min}$, the supernatant was discarded and the bacteria were resuspended and diluted into sterile saline to achieve a concentration of $\sim 5 \times 10^{7}$ c.f.u. $\mathrm{ml}^{-1}$.

Mouse wound infection model. Vancomycin (molecular mass 1620.67 Da) and daptomycin (molecular mass $1485.7 \mathrm{Da}$ ) were chosen for the in vivo studies as they were shown to act synergistically with HSM1 (molecular mass 612.24 Da) in the in vitro studies. For each strain, the study included an infected or uninfected group that did not receive any treatment, a group that received local treatment of an HSM1-soaked Allevyn dressing (Smith \& Nephew), a group that received intraperitoneal vancomycin $\left(7 \mathrm{mg} \mathrm{kg}^{-1}\right)$, a group that received intraperitoneal daptomycin $\left(7 \mathrm{mg} \mathrm{kg}^{-1}\right)$, a group that received local HSM1 treatment plus intraperitoneal vancomycin $\left(7 \mathrm{mg} \mathrm{kg}^{-1}\right)$ and a group that received local HSM1 treatment plus intraperitoneal daptomycin $\left(7 \mathrm{mg} \mathrm{kg}^{-1}\right)$. HSM1 absorption was obtained immediately before implantation by soaking the Allevyn dressing for $20 \mathrm{~min}$ in a sterile solution of HSM1 (10 mg ml${ }^{-1}$ ) (Simonetti et al., 2008).

The mice were anaesthetized by intramuscular injection of ketamine $\left[50 \mathrm{mg}(\mathrm{kg} \text { body weight })^{-1}\right]$ and xylazine $\left[8 \mathrm{mg}(\mathrm{kg} \text { body weight })^{-1}\right]$ and the hair on the back was shaved and the skin cleansed with $10 \%$ povidone-iodine solution. Using a $1 \times 2 \mathrm{~cm}$ template, one fullthickness wound was established through the panniculus carnosus on the back subcutaneous tissue of each animal. A small piece of gauze was placed over each wound and inoculated with $5 \times 10^{7}$ c.f.u. of the control strains in a volume of $1 \mathrm{ml}$ (Simonetti et al., 2008). The pocket was closed by means of skin clips (Kugelberg et al., 2005). This procedure resulted in a local abscess at $24 \mathrm{~h}$. One wound was created per animal. The animals were returned to individual cages and thoroughly examined daily. After $24 \mathrm{~h}$, the wound was opened in control animals, the gauze was removed for quantitative bacterial culture and treatment was initiated. Intraperitoneal vancomycin or daptomycin was administered daily for 7 days, whilst topical treatment was applied every 2 days.

Animals were euthanized and a $1 \times 2 \mathrm{~cm}$ area of skin, including the wound, was excised aseptically. Skin samples were divided into two. One piece was used for histological examination and the other was homogenized in $1 \mathrm{ml}$ PBS using a stomacher. Quantification of viable bacteria was performed by culturing serial dilutions $(0.1 \mathrm{ml})$ of the bacterial suspension on blood agar plates. All plates were incubated at $37{ }^{\circ} \mathrm{C}$ for $48 \mathrm{~h}$ and evaluated for the presence of bacteria. The organisms were quantified by counting the number of c.f.u. per plate. The limit of detection for this method was approximately 10 c.f.u. (g tissue $)^{-1}$.

Statistical analysis. All results are presented as group means \pm SD. Statistical analysis was performed using analysis of variance (ANOVA). Significance was accepted when the $P$ value was $<0.05$.

\section{RESULTS}

All isolates were inhibited by HSM1 at concentrations of 4-32 $\mathrm{mg} \mathrm{l}^{-1}$. In detail, for the control strains MSSA ATCC 29213, MRSA ATCC 43300, E. faecalis ATCC 29212, E. faecalis ATCC 51299, R. equi ATCC 6939 and S. pyogenes ATCC 19615, the peptide exhibited MICs of 4, 8, 16, 32, 4 and $4 \mathrm{mg} \mathrm{l}^{-1}$, and MBCs of 16, 16, 32, 64, 16 and $8 \mathrm{mg} \mathrm{l}^{-1}$, respectively (Table 1). Interestingly, for $R$. equi, HSM1 showed $\mathrm{MBC}$ values of 4 and $16 \mathrm{mg} \mathrm{l}^{-1} \quad\left(\mathrm{MBC}_{50}\right.$ and $\mathrm{MBC}_{90}$ ), whilst the other antimicrobial agents had $\mathrm{MBC}$ values that were much higher than their MIC values (Table 1).

Killing by HSM1 was shown to be very rapid: its activity against staphylococci and enterococci was complete after a 30 min exposure period at a concentration of $2 \times \mathrm{MIC}$, and against $R$. equi after $40 \mathrm{~min}$ and against $S$. pyogenes ATCC 19615 after $20 \mathrm{~min}$ at the same concentration (Fig. 1).

In the combination studies, synergy was observed only for the combination of HSM1 with vancomycin or daptomycin. FIC indices of $0.385,0.458,0.385$ and 0.312 were observed by testing HSM1 combined with vancomycin or daptomycin for MSSA, VS E. faecalis, $R$. equi and $S$. pyogenes, respectively. In contrast, experiments with the other antibiotics gave FIC index values between 0.917 and 2.0 (Table 2).

The cytotoxic effect of HSM1 was effectively absent at the concentrations tested with a cytotoxicity of $3.5 \%$.

In the in vivo setting, for staphylococcal infection, mean bacterial numbers in challenged but untreated controls $\left(\right.$ mean $\pm S D, 6.7 \times 10^{7} \pm 0.9 \times 10^{7}$ c.f.u. $\left.\mathrm{ml}^{-1}\right)$ were significantly higher than those recovered from all treatment groups (Table 3). Specifically, HSM1 alone reduced bacterial numbers to $4.4 \times 10^{4} \pm 0.7 \times 10^{4}$ c.f.u. $\mathrm{ml}^{-1}$. A reduction in bacterial load was also obtained following administration of intraperitoneal daptomycin or vancomycin $\left(3.8 \times 10^{3} \pm 0.2 \times 10^{3}\right.$ and $4.0 \times 10^{3} \pm 0.5 \times 10^{3}$, respectively). However, the greatest bacterial inhibition was obtained in the group that received topical HSM1 and intraperitoneal daptomycin or vancomycin $(17 \pm 2$ and $22 \pm 2$, respectively; $P<0.01)$.

For enterococcal infection, we observed the same pattern of results (Table 4). All groups treated with daptomycin or vancomycin alone showed statistically significant results compared with the control group $(P<0.01)$. Both vancomycin and daptomycin also showed a statistically significant higher level of activity than HSM1 $(P<0.01)$. Similar to the staphylococcal group infection, the two groups treated 
Table 1. MICs and MBCs of HSM1 and clinically used antibiotics for 100 clinical isolates

\begin{tabular}{|c|c|c|c|c|c|c|}
\hline \multirow[t]{2}{*}{ Strains (no.)/agent } & \multicolumn{3}{|c|}{$\operatorname{MIC}\left(\mathrm{mg} \mathrm{l}^{-1}\right)$} & \multicolumn{3}{|c|}{$\operatorname{MBC}\left(\mathrm{mg} \mathrm{l}^{-1}\right)$} \\
\hline & Range & $50 \%$ & $90 \%$ & Range & $50 \%$ & $90 \%$ \\
\hline HSM1 & $2-16$ & 4 & 8 & $4-32$ & 8 & 16 \\
\hline Imipenem & $2-128$ & 16 & 128 & $8-256$ & 64 & 256 \\
\hline Doxycycline & $0.50-32$ & 4 & 16 & $2-64$ & 8 & 32 \\
\hline Linezolid & $0.25-2$ & 0.5 & 1 & $2-16$ & 8 & 16 \\
\hline Vancomycin & $0.12-4$ & 1 & 2 & $0.50-4$ & 1 & 2 \\
\hline Daptomycin & $0.25-2$ & 1 & 2 & $0.50-4$ & 1 & 2 \\
\hline \multicolumn{7}{|l|}{ MSSA $(n=20)$} \\
\hline HSM1 & $2-8$ & 2 & 4 & $2-16$ & 8 & 16 \\
\hline Linezolid & $0.12-2$ & 0.5 & 2 & $2-16$ & 8 & 16 \\
\hline Vancomycin & $0.12-2$ & 0.5 & 1 & $0.50-2$ & 0.5 & 2 \\
\hline Daptomycin & $0.12-2$ & 0.5 & 1 & $0.50-2$ & 0.5 & 2 \\
\hline \multicolumn{7}{|l|}{ VS E. faecalis $(n=20)$} \\
\hline HSM1 & $2-32$ & 8 & 16 & $2-32$ & 16 & 32 \\
\hline Imipenem & $1-64$ & 4 & 16 & $4-256$ & 16 & 64 \\
\hline Doxycycline & $1-32$ & 8 & 16 & $8-128$ & 16 & 64 \\
\hline Erythromycin & $4-128$ & 8 & 32 & $8-256$ & 16 & 128 \\
\hline Ciprofloxacin & $1-16$ & 4 & 8 & $1-32$ & 8 & 16 \\
\hline Linezolid & $0.50-4$ & 1 & 2 & $2-32$ & 8 & 16 \\
\hline Vancomycin & $0.25-4$ & 1 & 2 & $2-32$ & 4 & 16 \\
\hline Linezolid & $0.50-4$ & 1 & 2 & $2-32$ & 8 & 32 \\
\hline Vancomycin & $32-128$ & 32 & 64 & $64->256$ & 64 & $>256$ \\
\hline Daptomycin & $0.50-2$ & 1 & 2 & $2-32$ & 8 & 32 \\
\hline \multicolumn{7}{|l|}{ S. pyogenes $(n=20)$} \\
\hline HSM1 & $1-8$ & 2 & 4 & $2-16$ & 4 & 8 \\
\hline Imipenem & $0.25-2$ & 0.50 & 1 & $0.5-4$ & 1 & 4 \\
\hline Doxycycline & $0.50-8$ & 4 & 8 & $1-32$ & 8 & 16 \\
\hline Erythromycin & $0.50-8$ & 2 & 8 & $1-32$ & 8 & 32 \\
\hline Ciprofloxacin & $0.50-8$ & 2 & 8 & $1-16$ & 8 & 16 \\
\hline Linezolid & $0.12-2$ & 0.5 & 1 & $2-32$ & 8 & 16 \\
\hline Vancomycin & $0.25-2$ & 0.5 & 1 & $1-16$ & 4 & 16 \\
\hline Daptomycin & $0.12-1$ & 0.5 & 1 & $0.50-2$ & 1 & 2 \\
\hline \multicolumn{7}{|l|}{ R. equi $(n=10)$} \\
\hline HSM1 & $2-8$ & 2 & 4 & $2-16$ & 4 & 16 \\
\hline Imipenem & $0.25-2$ & 0.25 & 1 & $2-32$ & 8 & 32 \\
\hline Doxycycline & $0.50-4$ & 1 & 2 & $8-256$ & 32 & 128 \\
\hline Erythromycin & $0.50-2$ & 0.50 & 2 & $16-128$ & 32 & 64 \\
\hline Ciprofloxacin & $0.50-4$ & 1 & 2 & $2-128$ & 16 & 64 \\
\hline Linezolid & $0.25-2$ & 0.50 & 1 & $8-64$ & 16 & 64 \\
\hline Vancomycin & $0.25-2$ & 0.50 & 1 & $2-16$ & 8 & 16 \\
\hline Daptomycin & $0.50-4$ & 0.50 & 2 & $2-16$ & 8 & 16 \\
\hline
\end{tabular}




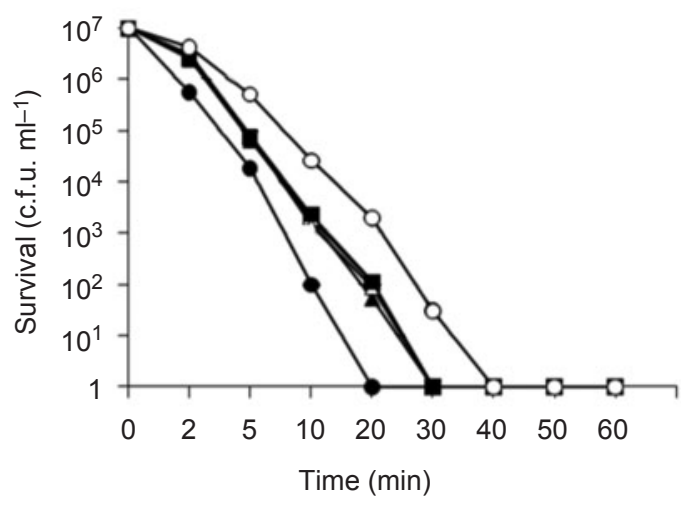

Fig. 1. Time-kill kinetics of HSM1 against the quality-control strains MSSA ATCC $29213(\triangle)$, MRSA ATCC 43300 (A), VS E. faecalis ATCC $29212(\square)$, VR E. faecalis ATCC $51299(\mathbf{\square}), R$. equi ATCC $6939(\bigcirc)$ and S. pyogenes ATCC $19615(\bullet)$.

with the drug combination showed the highest efficacy in inhibition of the bacterial load $(P<0.001)$.

\section{DISCUSSION}

The ongoing explosion of antibiotic-resistant infections continues to plague global health care (Grundmann et al., 2006; Maviglia et al., 2009; Spellberg et al., 2008). The emergence of bacterial resistance to conventional antibiotics has become commonplace and has heightened the need for new drugs with broader activity that can be used in infections that are unresponsive to common antibiotics (Spellberg et al., 2008). One way to overcome the problems of the emergence of resistance, to broaden the antibacterial spectrum of activity and to reduce the increasing selection pressure by antibiotics on Gram-positive pathogens is the use of new antimicrobial compounds and/or the use of synergistic antimicrobials (Spellberg et al., 2008).

In this study, we explored the antimicrobial activity and possible synergy between HSM1 and clinically used antibiotics in vitro and in vivo. Overall, our in vitro data showed that staphylococci, $R$. equi and streptococci were susceptible to this compound, although the enterococci showed a lower susceptibility. Interestingly, HSM1 was found to be equally active against both susceptible and multidrug-resistant clinical isolates. Our data showed that, for $R$. equi, the MBC values for HSM1 were much lower than the MBC values for the antibiotics. This finding is interesting when considering that, despite the good in vitro activities of traditional antibiotics, therapy is often partially effective and relapses occur during the course of the disease. Moreover, time-kill studies showed a rapid bactericidal effect, despite the inactivation of $R$. equi appearing to be slower than that observed for the other Gram-positive cocci. In vitro synergy studies showed a positive interaction between HSM1 and vancomycin or daptomycin, and no antagonism was observed for any of the combinations tested. To corroborate the data obtained in vitro, we decided to perform an animal model of surgical wound infection using a staphylococcal and an enterococcal strain. The drugs we chose to use in the in vivo model were vancomycin and daptomycin as they were shown to be synergistic with HSM1 in the in vitro studies.

For both bacterial strains, all groups treated with single drugs showed a statistically significant result compared with the control group. HSM1 showed good activity against both the staphylococcal and the enterococcal isolate, although for the enterococcal infection it had a significantly lower efficacy than vancomycin and daptomycin. Interestingly, our data indicated that the highest antibacterial efficacy was in the groups treated with HSM1 together with parenteral vancomycin or daptomycin.

The interaction between saponins and microbial glycopeptides or lipopeptides has not yet been studied extensively and the mechanism of this synergism is currently unknown. However, several reasons may explain this phenomenon. The biological activity of saponins is normally defined in terms of their ability to form complexes with sterols, to permeabilize membranes or to inhibit the growth of fungi or bacteria. Saponins form

Table 2. Results of interaction studies between HSM1 and other drugs

HSM1 was tested with each of the antimicrobial agents shown. The concentration ranges tested were $0.125-64 \mathrm{mg} 1^{-1}$ for HSM1 and $0.25-256 \mathrm{mg}$ $1^{-1}$ for the other antimicrobial agents. Six strains were tested for each genus. No antagonism was detected in any of the combinations tested.

\begin{tabular}{|lcccc|}
\hline \multirow{2}{*}{ Agent } & \multicolumn{3}{c|}{ FIC index (range) } \\
\cline { 2 - 5 } & MSSA & VS E. faecalis & R. equi & \multicolumn{1}{c|}{ S. pyogenes } \\
\hline Imipenem & $1.458(1.250-2.000)$ & $0.917(0.750-1.250)$ & $1.292(0.750-2.000)$ & $1.292(0.750-2.00)$ \\
Doxycycline & $1.167(1.000-1.500)$ & $1.500(1.000-2.000)$ & $2.000(1.000-2.000)$ & $1.167(1.000-1.50)$ \\
Erythromycin & $1.292(0.750-2.000)$ & $1.833(1.500-2.000)$ & $1.500(1.000-2.000)$ & $1.292(0.750-2.00)$ \\
Ciprofloxacin & $1.833(1.500-2.000)$ & $1.458(1.250-2.000)$ & $1.500(1.000-2.000)$ & $1.500(1.000-2.00)$ \\
Linezolid & $1.500(1.000-2.000)$ & $1.458(1.250-2.000)$ & $1.833(1.500-2.000)$ & $2.000(1.000-2.00)$ \\
Vancomycin & $0.385(0.187-0.500)$ & $0.458(0.312-0.750)$ & $0.385(0.187-0.500)$ & $0.312(0.187-0.50)$ \\
Daptomycin & $0.385(0.187-0.500)$ & $0.385(0.187-0.500)$ & $0.458(0.312-0.750)$ & $0.312(0.187-0.50)$ \\
\hline
\end{tabular}


Table 3. Quantitative culture of excised tissues after drug administration in staphylococcal wound infections

\begin{tabular}{|lc|}
\hline Treatment & c.f.u. ml$^{-1}$ \\
\hline Uninfected & $<10$ \\
Infected untreated & $6.7 \times 10^{7} \pm 0.9 \times 10^{7}$ \\
HSM1 $\left(1 \mathrm{mg} \mathrm{kg}^{-1}\right)$ & $4.4 \times 10^{4} \pm 0.7 \times 10^{4}$ \\
Vancomycin $\left(7 \mathrm{mg} \mathrm{kg}^{-1}\right)^{\star}$ & $4.0 \times 10^{3} \pm 0.5 \times 10^{3}$ \\
Daptomycin $\left(7 \mathrm{mg} \mathrm{kg}^{-1}\right)^{\star}$ & $3.8 \times 10^{3} \pm 0.2 \times 10^{3}$ \\
HSM1 $\left(1 \mathrm{mg} \mathrm{kg}^{-1}\right) \mathrm{plus} \mathrm{vancomycin}^{-1}$ & $22 \pm 2$ \\
$(7 \mathrm{mg} \mathrm{kg})^{*} \dagger$ & \\
HSM1 $\left(1 \mathrm{mg} \mathrm{kg}^{-1}\right)$ plus daptomycin & \\
$\left.(7 \mathrm{mg} \mathrm{kg})^{-1}\right)^{*}$ & \\
\hline
\end{tabular}

${ }^{*}$ Groups treated with intraperitoneal antibiotics showed a significant improvement compared with the group without treatment (ANOVA, $P<0.001)$.

†Groups treated with combined antibiotics showed a significant improvement compared with groups treated with each drug alone (ANOVA, $P<0.001$ ).

complexes with sterols and cause sterol-dependent membrane permeabilization. The antimicrobial activity of saponins is generally attributed to these membranepermeabilizing properties (Datta et al., 2009; Yang et al., 2006). Studies have demonstrated that membrane impermeability plays an important role in resistance to antibiotics. Therefore, if the entry of antibiotics into the cytoplasm is increased by changes in the permeability of the plasma membrane, their antimicrobial activity could be increased. In other words, when sublethal doses of HSM1 interact with

Table 4. Quantitative culture of excised tissues after drug administration in enterococcal wound infections

\begin{tabular}{|c|c|}
\hline Treatment & c.f.u. $\mathrm{ml}^{-1}$ \\
\hline Uninfected & $<10$ \\
\hline Infected untreated & $8.3 \times 10^{7} \pm 2.0 \times 10^{7}$ \\
\hline HSM1 $\left(1 \mathrm{mg} \mathrm{kg}^{-1}\right)$ & $2.1 \times 10^{5} \pm 0.3 \times 10^{5}$ \\
\hline Vancomycin $\left(7 \mathrm{mg} \mathrm{kg}^{-1}\right)^{\star} \dagger$ & $5.6 \times 10^{3} \pm 1.1 \times 10^{3}$ \\
\hline Daptomycin $\left(7 \mathrm{mg} \mathrm{kg}^{-1}\right)^{\star} \dagger$ & $4.3 \times 10^{3} \pm 0.3 \times 10^{3}$ \\
\hline $\begin{array}{l}\text { HSM1 }\left(1 \mathrm{mg} \mathrm{kg}^{-1}\right) \text { plus vancomycin } \\
\left(7 \mathrm{mg} \mathrm{kg}^{-1}\right)^{\star} \dagger \ddagger\end{array}$ & $32 \pm 8$ \\
\hline $\begin{array}{l}\text { HSM1 }\left(1 \mathrm{mg} \mathrm{kg}^{-1}\right) \text { plus daptomycin } \\
\left(7 \mathrm{mg} \mathrm{kg}^{-1}\right)^{* \dagger \neq}\end{array}$ & $23 \pm 4$ \\
\hline
\end{tabular}

${ }^{\star}$ Groups treated with intraperitoneal antibiotics showed a significant improvement compared with the group without treatment (ANOVA, $P<0.001)$.

$\dagger$ Groups treated with intraperitoneal antibiotics showed a significant improvement compared with the HSM1-treated group (ANOVA, $P<0.001)$.

‡Groups treated with combined antibiotics showed a significant improvement compared with groups treated with each drug alone (ANOVA, $P<0.001$ ). the membrane, this increases the permeability of the plasma membrane to clinically used antibiotics. The mechanism by which such a combination achieves synergy is believed to be by facilitating the entry of the antimicrobial compounds into cells after the partial disruption of the cell membrane through its action. Moreover, it is possible that the positive interaction is a result of a combined effect of increased access to the intracellular target for vancomycin or daptomycin and the secondary effects of the saponins themselves (Datta et al., 2009; Sung \& Lee, 2008).

Saponins have a broad range of properties including antimicrobial and anti-insect activities, and there is good evidence that they contribute to plant defence. They have also been associated with a variety of effects on human health, such as lowering cholesterol, enhancing immune responses as cancer chemotherapy agents and protecting against acute hepatic failure, and pathogenic fungi and other micro-organisms (Qiang et al., 2010; Yang et al., 2006; Ying-Wan et al., 2010).

Finally, the high level of in vitro activity and in vivo efficacy, together with the synergistic interactions with vancomycin and daptomycin, suggest that HSM1 may be a promising candidate for additional in vivo studies in the treatment of wound infections due to Gram-positive cocci.

\section{ACKNOWLEDGEMENTS}

This work was supported by the Italian Ministry of Education, University and Research (PRIN 2007) and by grant POIG.01.01.0214-102/09-01 part financed by the European Union within the European Regional Development Fund.

\section{REFERENCES}

Aremu, A. O., Fawole, O. A., Chukwujekwu, J. C., Light, M. E., Finnie, J. F. \& Van Staden, J. (2010). In vitro antimicrobial, anthelmintic and cyclooxygenase-inhibitory activities and phytochemical analysis of Leucosidea sericea. J Ethnopharmacol 131, 22-27.

Bouza, E. (2009). New therapeutic choices for infections caused by methicillin-resistant Staphylococcus aureus. Clin Microbiol Infect 15 (Suppl. 7), 44-52.

Bratzler, D. W., Houck, P. M. for the Surgical Infection Prevention Guidelines Writers Workgroup (2004). Antimicrobial prophylaxis for surgery: an advisory statement from the National Surgical Infection Prevention Project. Clin Infect Dis 38, 1706-1715.

Burke, J. P. (2003). Infection control - a problem for patient safety. $N$ Engl J Med 348, 651-656.

NCCLS (2003). Methods for Dilution Antimicrobial Susceptibility Tests for Bacteria that Grow Aerobically; Approved Standard. M7-A6. Villanova, PA: National Committee for Clinical Laboratory Standards.

Cormican, M. G. \& Jones, R. N. (1996). Emerging resistance to antimicrobial agents in Gram-positive bacteria. Enterococci, staphylococci and nonpneumococcal streptococci. Drugs 51 (Suppl. 1), 6-12.

Datta, S., Maitra, S., Gayen, P. \& Sinha Babu, S. P. (2009). Improved efficacy of tetracycline by acaciasides on Dirofilaria immitis. Parasitol Res 105, 697-702. 
Di Liberto, M., Svetaz, L., Furlán, R. L., Zacchino, S. A., Delporte, C., Novoa, M. A., Asencio, M. \& Cassels, B. K. (2010). Antifungal activity of saponin-rich extracts of Phytolacca dioica and of the sapogenins obtained through hydrolysis. Nat Prod Commun 5, 1013-1018.

Eliopoulos, G. M. \& Moellering, R. C., Jr (1996). Antimicrobial combinations. In Antibiotics in Laboratory Medicine, pp. 330-393. Edited by V. Lorian. Baltimore, MD: Williams \& Wilkins.

Fisher, K. \& Phillips, C. (2009). The ecology, epidemiology and virulence of Enterococcus. Microbiology 155, 1749-1757.

Grundmann, H., Aires-de-Sousa, M., Boyce, J. \& Tiemersma, E. (2006). Emergence and resurgence of meticillin-resistant Staphylococcus aureus as a public-health threat. Lancet 368, 874-885.

Hirsch, T., Koerber, A., Jacobsen, F., Dissemond, J., Steinau, H. U., Gatermann, S., Al-Benna, S., Kesting, M., Seipp, H. M. \& Steinstraesser, L. (2010). Evaluation of toxic side effects of clinically used skin antiseptics in vitro. J Surg Res 164, 344-350.

Kugelberg, E., Norström, T., Petersen, T. K., Duvold, T., Andersson, D. I. \& Hughes, D. (2005). Establishment of a superficial skin infection model in mice by using Staphylococcus aureus and Streptococcus pyogenes. Antimicrob Agents Chemother 49, 3435-3441.

Linden, P. K. (1998). Clinical implications of nosocomial Grampositive bacteremia and superimposed antimicrobial resistance. $\mathrm{Am} \mathrm{J}$ Med 104, 24S-33S.

Maviglia, R., Nestorini, R. \& Pennisi, M. (2009). Role of old antibiotics in multidrug resistant bacterial infections. Curr Drug Targets 10, 895905.

Moellering, R. C., Jr (1998). Problems with antimicrobial resistance in Gram-positive cocci. Clin Infect Dis 26, 1177-1178.

Myszka, H., Bednarczyk, D., Najder, M. \& Kaca, W. (2003). Synthesis and induction of apoptosis in B cell chronic leukemia by diosgenyl 2amino-2-deoxy- $\beta$-D-glucopyranoside hydrochloride and its derivatives. Carbohydr Res 338, 133-141.

Qi, X., Bakht, S., Qin, B., Leggett, M., Hemmings, A., Mellon, F., Eagles, J., Werck-Reichhart, D., Schaller, H. \& other authors (2006). A different function for a member of an ancient and highly conserved cytochrome P450 family: from essential sterols to plant defense. Proc Natl Acad Sci U S A 103, 18848-18853.
Qiang, H., Zhang, C., Shi, Z.-B., Yang, H.-Q. \& Wang, K.-Z. (2010). Protective effects and mechanism of Panax notoginseng saponins on oxidative stress-induced damage and apoptosis of rabbit bone marrow stromal cells. Chin J Integr Med 16, 525-530.

Raad, I., Alrahwan, A. \& Rolston, K. (1998). Staphylococcus epidermidis: emerging resistance and need for alternative agents. Clin Infect Dis 26, 1182-1187.

Saleem, M., Nazir, M., Ali, M. S., Hussain, H., Lee, Y. S., Riaz, N. \& Jabbar, A. (2010). Antimicrobial natural products: an update on future antibiotic drug candidates. Nat Prod Rep 27, 238-254.

Simonetti, O., Cirioni, O., Ghiselli, R., Goteri, G., Scalise, A., Orlando, F., Silvestri, C., Riva, A., Saba, V. \& other authors (2008). RNAIIIinhibiting peptide enhances healing of wounds infected with methicillin-resistant Staphylococcus aureus. Antimicrob Agents Chemother 52, 2205-2211.

Simons, V., Morrissey, J. P., Latijnhouwers, M., Csukai, M., Cleaver, A., Yarrow, C. \& Osbourn, A. (2006). Dual effects of plant steroidal alkaloids on Saccharomyces cerevisiae. Antimicrob Agents Chemother 50, 2732-2740.

Spellberg, B., Guidos, R., Gilbert, D., Bradley, J., Boucher, H. W., Scheld, W. M., Bartlett, J. G., Edwards, J., Jr \& Infectious Diseases Society of America (2008). The epidemic of antibiotic-resistant infections: a call to action for the medical community from the Infectious Diseases Society of America. Clin Infect Dis 46, 155-164.

Sung, W. S. \& Lee, D. G. (2008). The combination effect of Korean red ginseng saponins with kanamycin and cefotaxime against methicillinresistant Staphylococcus aureus. Biol Pharm Bull 31, 1614-1617.

Wallace, R. J. (2004). Antimicrobial properties of plant secondary metabolites. Proc Nutr Soc 63, 621-629.

Yang, C.-R., Zhang, Y., Jacob, M. R., Khan, S. I., Zhang, Y.-J. \& Li, X.-C. (2006). Antifungal activity of C-27 steroidal saponins. Antimicrob Agents Chemother 50, 1710-1714.

Ying-Wan, Wu, Y.-L., Feng, X.-C., Lian, L.-H., Jiang, Y.-Z. \& Nan, J.-X. (2010). The protective effects of total saponins from Ornithogalum saundersiae (Liliaceae) on acute hepatic failure induced by lipopolysaccharide and D-galactosamine in mice. J Ethnopharmacol 132, 450455 . 